\title{
AETIOLOGICAL STUDY OF PLEURAL EFFUSION BY CONVENTIONAL METHODS-ITS CLINICAL PRESENTATION ALONG WITH RADIOLOGICAL, BIOCHEMICAL AND CYTOLOGICAL CORRELATION OF 60 CASES OF PLEURAL EFFUSION
}

\author{
Midde Ranga Raja Rao ${ }^{1}$ Kuna Mohan Babu², Cheekatla Lakshmi Navya ${ }^{3}$ \\ ${ }_{1}^{1}$ Associate Professor, Department of General Medicine, Katuri Medical College and Hospital. \\ 2Junior Resident, Department of General Medicine, Katuri Medical College and Hospital. \\ JJunior Resident, Department of General Medicine, Katuri Medical College and Hospital.
}

\begin{tabular}{l}
\hline ABSTRACT \\
\hline BACKGROUND \\
Pleural effusion is the excessive or abnormal accumulation of fluid in the pleural space. Pleural effusion is routinely facing \\
problem in practice by general physician and chest physician. Pleural effusion often present as common diagnostic dilemma as no \\
cause can be found in many cases in spite of careful evaluation. For better management of cases to obtain knowledge of clinical \\
history and clinical signs of pleural effusion along with radiological, biochemical, and cytological evaluation of pleural fluid help in \\
narrowing the diagnosis.
\end{tabular}

\section{METHODS}

In this prospective study of 60 patients with pleural effusion with respect to age, sex, presenting complaint, clinical history with radiological, biochemical, and cytological examination of pleural fluid are considered.

\section{RESULTS}

In this prospective study of 60 patients with pleural effusion, their age is 11 to 75 years and two third were men. The most common type of pleural effusion is exudative effusion. The most common cause of exudative effusion in this study were tuberculosis (36), followed by malignancy (9), transudative (8), synpneumonic (5), and 2 cases of empyema (2). Pleural effusion was commonly seen in male patient with maximum number of cases in age group 31-50. Pleuritic chest pain, fever, cough, and breathlessness were common presenting complaint. The commonest clinical sign was stony dullness to percussion. Right-sided effusions were more common. Majority had moderate amount of pleural effusions. Blood count and ESR were significantly elevated in exudatives. Pleural fluid cytology revealed elevated lymphocytes in tubercular and polymorphs in acute infections. Cytology for malignant cells were diagnostic in 4 cases. ADA was significantly elevated in tubercular pleural effusion. Exudatives had decreased glucose, but increased protein, $\mathrm{LDH}$, and cholesterol compared to transudatives.

\section{CONCLUSION}

Tubercular effusion remains the commonest aetiology of all exudative effusions in our study. It involves the young and is associated with fever and cough as the most common presenting symptom. Malignant effusion was seen in older age group with cough and dyspnoea as common symptoms. Massive effusion with haemorrhagic pleural fluid is commonly associated with malignant effusion.

\section{KEYWORDS}

Exudative, Transudative, Tubercular, Malignant, Synpneumonic, Empyema, Pleural Effusion.

HOW TO CITE THIS ARTICLE: Rao MRR, Babu KM, Navya CL. Aetiological study of pleural effusion by conventional methods-its clinical presentation along with radiological, biochemical and cytological correlation of 60 cases of pleural effusion. J. Evolution Med. Dent. Sci. 2016;5(52):3420-3424, DOI: 10.14260/jemds/2016/790

\section{INTRODUCTION}

Pleural effusions are a common diagnostic problem in clinical practice as the list of causes is quite exhaustive. ${ }^{1}$ although sometimes they can be inferred from the clinical picture. The aetiological distribution of pleural effusions in various series depends on the geographical area, patient's age, and advances in the diagnostic methods and treatment of the underlying

Financial or Other, Competing Interest: None.

Submission 13-05-2016, Peer Review 08-06-2016,

Acceptance 13-06-2016, Published 30-06-2016.

Corresponding Author:

Dr. Midde Ranga Raja Rao,

Associate Professor,

Department of General Medicine,

Katuri Medical College and Hospital,

Chinakondrupadu,

Guntur, Andhra Pradesh.

E-mail: rangarajaraom@gmail.com

DOI: $10.14260 /$ jemds/2016/790 causes. The difficulty in determining the cause of pleural effusion is shown by the fact that in many series "unknown aetiology" constitutes nearly 15\%.2 Exudative effusions require to be separated into infectious causes, non-infectious causes, and malignancy. The most common causes in most series are infections and malignancy. In the West, the most common cause is parapneumonic effusions followed by malignancy. ${ }^{1}$ While in India, it is tubercular effusion followed by malignant effusion. ${ }^{3}$ and a very few due to parapneumonic effusion.

India has the highest prevalence of tuberculosis in the world with $2 / 3 \mathrm{rds}$ of all TB patients being in India. 4 Tuberculosis is the most common cause of effusion in India when compared to the West where malignancy and parapneumonic effusions are more common. ${ }^{3}$ Pleural tuberculosis is second in frequency after TB lymphadenitis. ${ }^{3}$ The clinical, biochemical, and cytological parameters of 
tubercular effusion are shared by malignancy both being exudates and predominantly lymphocytic effusions.

This can pose a significant diagnostic dilemma. Adenosine deaminase enzyme activity, gamma interferon, polymerase chain reaction, lysozyme measurement, pleural fluid tuberculous protein antibodies and various tumour markers like CA15-3, squamous cell carcinoma antigen, etc. have been used to differentiate TB from non-TB. Other diagnostic tests including flow cytometry, chromosomal analysis of malignant cells, LDH isoenzymes assay, and tumour marker assays, immunohistochemical tests and Carcinoembryonic Antigen (CEA), are used to differentiate between benign and malignant effusions ${ }^{5}$. Despite the availability of all tests, it might be necessary to avail of more invasive diagnostic tools like pleural biopsy or thoracoscopy to establish a diagnosis. Adenosine deaminase although shown to be promising in the West to differentiate tubercular from non-tubercular effusion.

\section{BACKGROUND AND OBJECTIVES}

For better management of cases to obtain knowledge of clinical history and clinical signs of pleural effusion along with radiological, biochemical, and cytological evaluation of pleural fluid help in narrowing the diagnosis.

1. To determine the aetiology of all pleural effusions by conventional methods.

2. To determine the utility of cytological, biochemical parameters in the evaluation of pleural effusions.

3. To determine the sensitivity of pleural fluid ADA in the diagnosis of tubercular pleural effusion.

4. To evaluate cytological profile of pleural effusion.

5. To evaluate the reliability and diagnostic efficacy of pleural glucose, total protein, lactate dehydrogenase, adenosine deaminase, and cholesterol in aetiological diagnosis of pleural effusion.

\section{METHODOLOGY}

\section{Source of Data}

The present study was conducted in the Katuri Medical College and Hospital, Chinakondrupadu, Guntur District on the patients with pleural effusions admitted during the period of December 2013 to June 2015.

\section{Sample Size}

60 cases.

\section{Sample Procedure}

Prospective study of pleural effusion.

\section{Study Duration}

December 2013 to June 2015.

\section{Inclusion Criteria}

1. Pleural effusion as per clinical findings.

2. Chest $x$-ray showing evidence of pleural effusion.

3. Age more than 10 years.

4. Patient who have given informed consent.

\section{Exclusion Criteria}

1. Patient who have undergone repeated pleurocentesis.

2. Minimal effusion without clinical and x-ray findings.

3. Patient age less than 10 years.

4. Patient who do not given their consent.

\section{Methods of Collection Data}

Along with routine blood and urine investigations, $\mathrm{x}$-ray chest PA view, ultrasound chest (and guided pleurocentesis), diagnostic pleurocentesis, pleural biopsy were also considered.

A detailed clinical history and general physical examination was done on all the patients. A chest radiograph posterior anterior view was done and the size of the effusion was estimated. If the size of the effusion was less than $2 / 3 \mathrm{rd}$, it was considered as not large and if it was more than $2 / 3$ the size was considered as large effusion respectively. An informed consent was taken from all the patients regarding pleurocentesis and pleural biopsy. The cases were recorded according to the proforma given later. Out of 60 cases of pleural effusion studied, 36 cases were tuberculous effusions and 24 cases were non-tubercular effusions.

The 60 Cases of Pleural Effusion were Divided into 5 Groups as under

- 36 cases of Tuberculous pleural effusion.

- 9 cases of Malignant pleural effusion.

- 8 cases of Transudative pleural effusion.

- 5 cases of Synpneumonic pleural effusion.

- 2 cases of Empyema.

\section{Group 1: Tuberculous Effusions}

There were 36 cases of tuberculous pleural effusion (23 male and 13 female). The diagnosis was based on factors like clinical features, x-ray evidence of parenchymal infiltrates, sputum AFB positivity, and pleural fluid analysis, response to ATT.

\section{Group 2: Malignant Effusions}

There were 9 cases of malignant effusion $(7$ males and 2 females). The diagnosis was based on clinical features, pleural fluid cytology for malignant cells and in cases with pleural effusion with a known malignancy at other sites with histopathological confirmation, other causes of pleural effusion being ruled out.

\section{Group 3: Transudative Effusion}

There were 8 cases of transudative effusion ( 6 males and 2 females)

- Congestive cardiac failure: The diagnosis was based on raised JVP, pedal oedema, tender hepatomegaly, bilateral basal crepitations, chest x-ray signs of lung congestion and cardiomegaly.

- Renal failure: Was diagnosed when there was raised blood urea and creatinine in the presence fluid overload.

- Nephrotic syndrome: This was diagnosed when the patient had proteinuria of $>3.5 \mathrm{gm} / 24 \mathrm{hrs}$, hypoalbuminaemia $<3.5 \mathrm{gm} / 1$ and oedema. Out of the 8 cases of transudative effusions, there were 2 cases of congestive cardiac failure, 2 cases of chronic renal failure, 2 cases of nephritic syndrome, and 2 cases of cirrhosis of liver.

\section{Group 4: Synpneumonic Effusion}

There were 5 cases of synpneumonic pleural effusion ( 4 males and 1 female). The diagnosis was established based on clinical features like fever, expectorant cough, signs of consolidation, chest $\mathrm{x}$-ray and response to antimicrobial therapy. 


\section{Group 5: Empyema}

These were 2 cases of empyema. The diagnosis was based on clinical feature, nature of pleural tapping, microbiological, and cytological confirmation.

\section{RESULTS}

In this prospective study of 60 patients with pleural effusion, their age is 11 to 75 years and two third were men. The most common type of pleural effusion is exudative effusion. The most common cause of exudative effusion in this study were tuberculosis (36), followed by malignancy (9), transudative (8), synpneumonic (5), and 2 cases of empyema (2).

\begin{tabular}{|c|c|c|c|}
\hline $\begin{array}{c}\text { Sl. } \\
\text { No. }\end{array}$ & $\begin{array}{c}\text { Type of } \\
\text { Effusion }\end{array}$ & $\begin{array}{c}\text { No. of } \\
\text { Cases }\end{array}$ & $\begin{array}{c}\text { Percentage } \\
\text { (\%) }\end{array}$ \\
\hline 1 & Tuberculous & 36 & 60.00 \\
\hline 2 & Malignant & 09 & 15.00 \\
\hline 3 & Transudative & 08 & 13.33 \\
\hline 4 & Synpneumonic & 05 & 8.3 \\
\hline 5 & Empyema & 02 & 3.33 \\
\hline
\end{tabular}

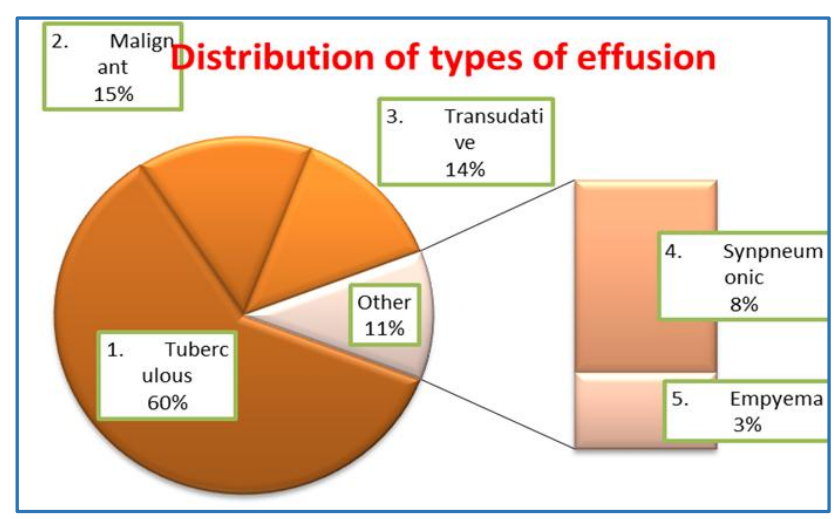

\section{Sex Distribution}

Among the 60 cases of pleural effusion, there were 39 males and 17 females. The male-female ratios in the various groups are as follows.

\begin{tabular}{|c|c|c|c|}
\hline \multirow{2}{*}{$\begin{array}{l}\text { Sl. } \\
\text { No. }\end{array}$} & \multirow{2}{*}{$\begin{array}{l}\text { Type of } \\
\text { Effusion }\end{array}$} & \multicolumn{2}{|c|}{ No. of Cases } \\
\hline & & Male & Female \\
\hline 1 & Tuberculous & 23 & 13 \\
\hline 2 & Malignant & 07 & 02 \\
\hline 3 & Transudative & 06 & 02 \\
\hline 4 & Synpneumonic & 04 & 01 \\
\hline \multirow[t]{2}{*}{5} & Empyema & 02 & 00 \\
\hline & Total & 42 & 18 \\
\hline \multicolumn{4}{|c|}{ Distribution of Types of Distribution } \\
\hline
\end{tabular}

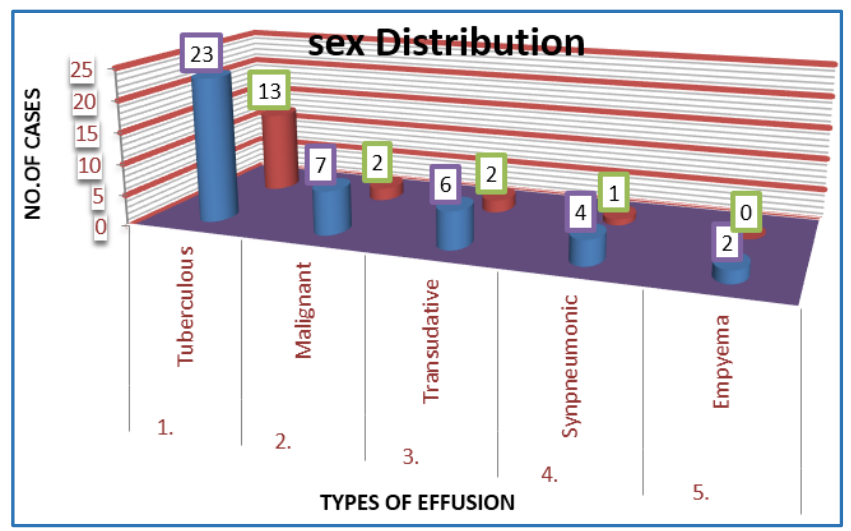

The Age distribution among the Cases are as follows

\begin{tabular}{|c|c|c|c|c|}
\hline \multirow{2}{*}{$\begin{array}{c}\text { Age } \\
\text { (Years) }\end{array}$} & \multicolumn{2}{|c|}{ No. of Cases } & \multirow{2}{*}{ Total } & $\begin{array}{c}\text { Percentage } \\
\text { (\%) }\end{array}$ \\
\cline { 2 - 5 } & Male & Female & & 6.66 \\
\hline $11-20$ & 01 & 03 & 04 & 16.66 \\
\hline $21-30$ & 05 & 05 & 10 & 20.00 \\
\hline $31-40$ & 09 & 03 & 12 & 21.66 \\
\hline $41-50$ & 10 & 03 & 13 & 20.00 \\
\hline $51-60$ & 10 & 02 & 12 & 10.00 \\
\hline $61-70$ & 05 & 01 & 06 & 5.00 \\
\hline $71-80$ & 02 & 01 & 03 & $\mathbf{1 0 0}$ \\
\hline Total & $\mathbf{4 2}$ & $\mathbf{1 8}$ & $\mathbf{6 0}$ & \\
\hline \multicolumn{7}{|c|}{ Age Distribution of Pleural Effusion } \\
\hline
\end{tabular}

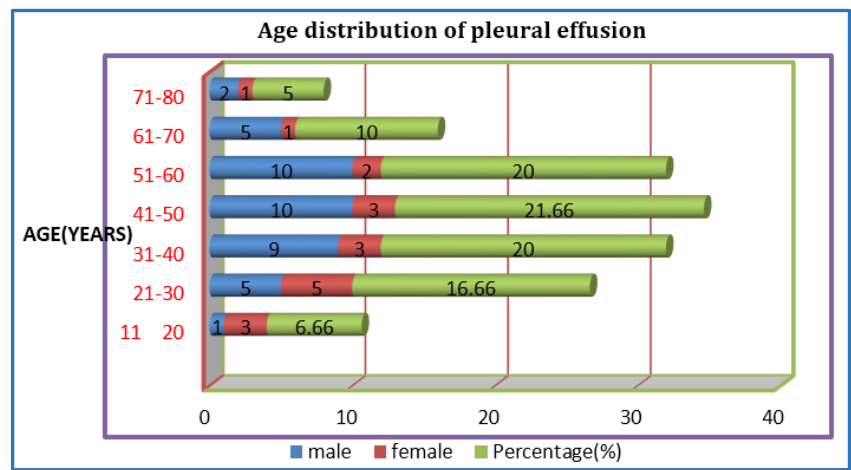

\section{Site of Effusion}

Out of the 60 cases of pleural effusion, 32 cases were right sided and 21 cases were left sided, 5 patients had bilateral effusions and 2 cases of empyema were on right side.

\begin{tabular}{|c|c|c|c|c|}
\hline & $\begin{array}{c}\text { Type of Pleural } \\
\text { Effusion }\end{array}$ & Left & Right & Bilateral \\
\hline 1 & Tuberculous & 16 & 20 & -- \\
\hline 2 & Malignant & 04 & 02 & 03 \\
\hline 3 & Synpneumonic & 01 & 04 & -- \\
\hline 4 & Transudative & -- & 03 & 05 \\
\hline 5 & Empyema & -- & 02 & -- \\
\hline & Total & $\mathbf{2 1}$ & $\mathbf{3 1}$ & $\mathbf{0 8}$ \\
\hline \multicolumn{2}{|c|}{ Percentage } & 35.00 & 51.66 & 13.33 \\
\hline \multicolumn{2}{|c|}{ Distribution of Site of Effusion in Pleural Effusion } \\
\hline
\end{tabular}

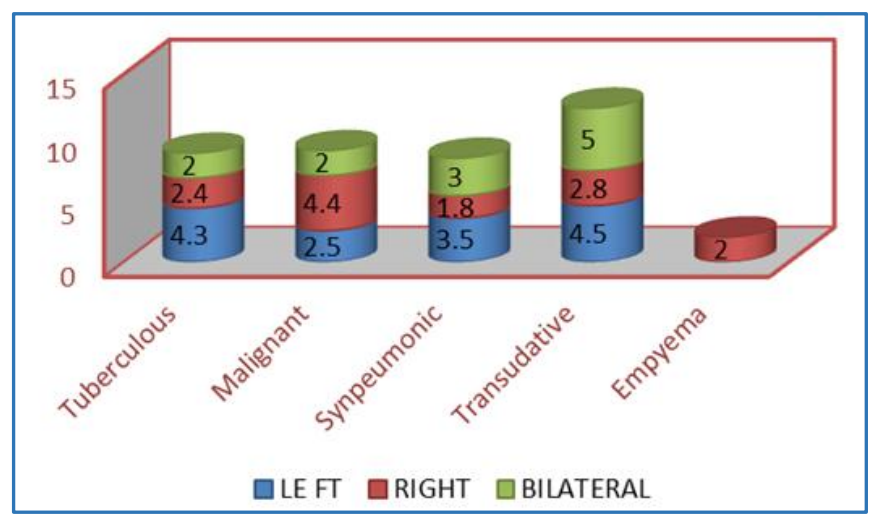

Distribution of Site of Effusion in Pleural Effusion

Majority had moderate amount of pleural effusions. Blood count and ESR were significantly elevated in exudatives. 
Pleural fluid cytology revealed elevated lymphocytes in tubercular and polymorphs in acute infections. Cytology for malignant cells were diagnostic in 4 cases.

\section{Pleural Fluid Cytology}

\begin{tabular}{|c|c|c|c|c|c|}
\hline $\begin{array}{r}\text { Sl. } \\
\text { No. }\end{array}$ & $\begin{array}{c}\text { Type of } \\
\text { Effusion }\end{array}$ & $\begin{array}{c}\text { No. of } \\
\text { Cases }\end{array}$ & $\begin{array}{c}\text { Cell } \\
\text { Count }\end{array}$ & $\begin{array}{c}\text { Cell type } \\
\text { Predominant }\end{array}$ & $\begin{array}{c}\text { Malign } \\
\text {-ant } \\
\text { Cells }\end{array}$ \\
\hline 1 & Tubercular & 36 & $\begin{array}{c}1062 \pm \\
504\end{array}$ & Lymphocytes & -- \\
\hline 2 & Malignant & 09 & $\begin{array}{c}1017 \pm \\
282\end{array}$ & Lymphocytes & $\begin{array}{c}\text { Posi- } \\
\text { tive in } \\
5 \text { cases }\end{array}$ \\
\hline 3 & Transudative & 08 & $\begin{array}{c}159 \pm \\
62\end{array}$ & $\begin{array}{c}\text { Monocytes and } \\
\text { lymphocytes }\end{array}$ & -- \\
\hline 4 & Synpneumonic & 05 & $\begin{array}{c}4520 \pm \\
1590\end{array}$ & Polymorphocytes & -- \\
\hline 5 & \multicolumn{6}{|c|}{ Empyema } & 02 & $\begin{array}{c}5930 \pm \\
273\end{array}$ & Polymorphocytes & -- \\
\hline \multicolumn{7}{|c|}{ Showing the Estimated Mean \pm SD of } \\
\hline
\end{tabular}

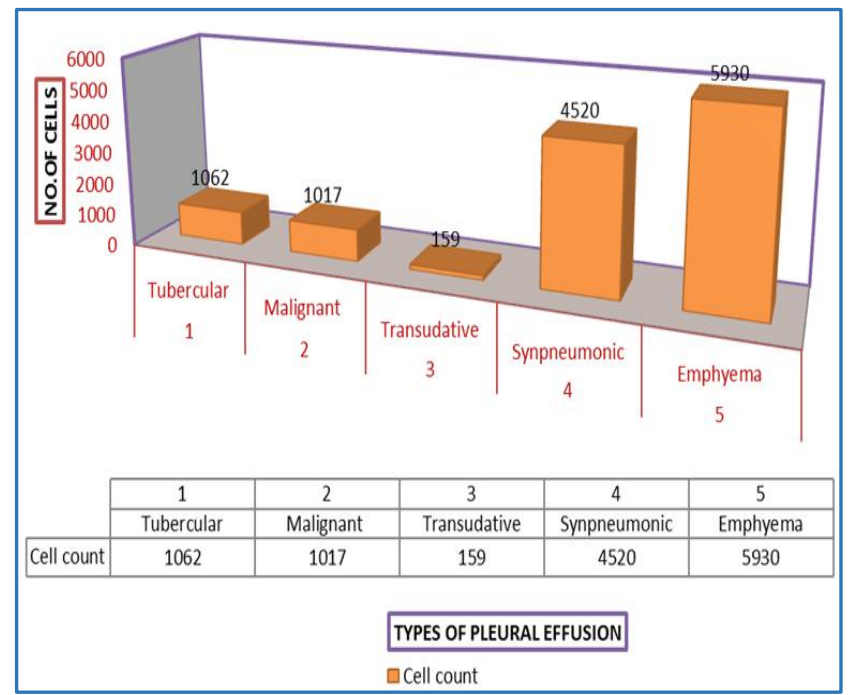

\begin{tabular}{|c|c|c|c|c|c|c|c|}
\hline $\begin{array}{c}\text { Sl. } \\
\text { No. }\end{array}$ & $\begin{array}{c}\text { Type of } \\
\text { Effusion }\end{array}$ & $\begin{array}{c}\text { No. of } \\
\text { Cases }\end{array}$ & \multicolumn{5}{|c|}{ Pleural Fluid } \\
\hline & & & GLU (mg/\%) & PROT (gm/\%) & LDH(U/L) & ADA(IU/L) & CHOL (mg/\%) \\
\hline 2 & Tubercular & 36 & $63 \pm 8.2$ & $4.3 \pm 1.5$ & $236.2 \pm 37$ & $78.7 \pm 19.9$ & $72.4 \pm 9.2$ \\
\hline 3 & Malignant & 09 & $53 \pm 3$ & $4.6 \pm 0.4$ & $340 \pm 46.5$ & $42.6 \pm 9.3$ & $76.1 \pm 10.2$ \\
\hline 4 & Transudative & 08 & $81 \pm 9$ & $2 \pm 0.8$ & $95 \pm 24.5$ & $28.4 \pm 8.2$ & $36.9 \pm 5.2$ \\
\hline 5 & Synpneumonic & 5 & $46 \pm 16$ & $4.5 \pm 0.4$ & $530 \pm 89$ & $42.2 \pm 21.3$ & $74.2 \pm 4.2$ \\
\hline 6 & Empyema & 02 & $29 \pm 4$ & $4.5 \pm 0.3$ & $1225 \pm 247$ & $30 \pm 6$ & $74.5 \pm 4.5$ \\
\hline \multicolumn{7}{|r|}{ Showing the Estimated Mean \pm SD of Pleural Fluid Glucose, Protein, LDH, ADA, Cholesterol } \\
\hline
\end{tabular}

ADA was significantly elevated in tubercular pleural effusion. Exudatives had decreased glucose, but increased protein, $\mathrm{LDH}$, and cholesterol compared to transudatives.

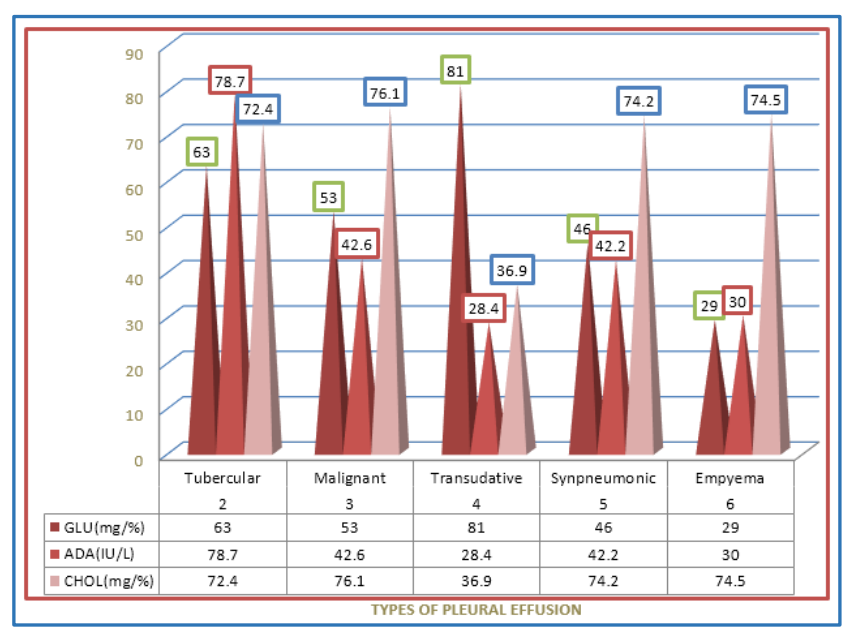

\section{DISCUSSION}

60 patients with pleural effusion were studied of which $60.52 \%$ were cases of tuberculous effusion and $39.48 \%$ were cases of non-tuberculous effusion. The present study is particularly relevant in our country as it has a high prevalence of tuberculosis.

\section{Aetiology of Pleural Effusion}

Out of the 60 cases of pleural effusion, which were studied, 36 cases were of tuberculous effusion. This was reflective of the high prevalence of tuberculosis in the area being studied. The remaining 24 cases were of malignant effusion (9 cases),
Transudative effusion (8 cases), synpneumonic effusion (5 cases) and 2 cases of empyema. In comparison, the sex distributions in some of the previous studies are: Prabhudesai. 6 tubercular effusion comprises $64 \%$ of infective cause and $8 \%$ were of empyema. In patients of age more than 40 years, malignant effusion was more common; A1 quatrain. ${ }^{7}$ common diagnosis was tubercular (37\%) followed by neoplasm (8\%), parapneumonic (14\%) and congestive cardiac failure (14\%); KZ Mamum ${ }^{8}$ also showed tubercular and malignancy where the major causes of pleural effusion; Valdes ${ }^{9}$ showed tubercular and transudative were commonest causes.

\section{Socioeconomic Status}

Most of the patients in this study belonged to the lower socioeconomic class. This is consistent with the fact that tuberculosis is a disease more commonly seen among people living in crowded unhygienic conditions.

\section{Presenting Complaints}

The following were the presenting complaints among the patients on admission. The commonest symptoms were cough (78.32\%) and breathlessness (74.76\%) followed by fever $71.20 \%$, weight loss $67.64 \%$, chest pain $44.50 \%$, loss of appetite $62.30 \%$, and haemoptysis $17.80 \%$. A small percentage $(32 \%)$ had various other symptoms like distension of abdomen, puffiness of face, swelling of feet, decreased urine output, and myalgia. Most of the patients with synpneumonic effusion had complaints of a short duration with an acute onset whereas those the tuberculous effusion and malignancy had complaints of a longer duration. In comparison to other 
studies: Follador E.C. 10 main complaints were fever (41/44), chest pain (41/44), and weight loss (34/44).

\section{Clinical Findings}

Out of the 60 patients with pleural effusion, 30 patients had a right-sided effusion and 20 patients had a left-sided effusion and 8 patients had bilateral effusion. 2 cases of empyema were on right side. In comparison to other studies: Al-Quarain. ${ }^{7}$ pleural effusion was more common in right side (55\%) than on the left (32\%); in Follador, ${ }^{10}$ both right and left side effusion were of equal distribution.

\section{Investigations}

In this study, out of the 36 cases of tuberculous effusion, in 9 cases acid fast bacilli could be demonstrated in the sputum by Ziehl-Neelsen staining (26.46\%). The detection of AFB in the sputum in the tuberculous depends upon the associated lung parenchymal lesion. In comparison to other study: Subhakar. $\mathrm{K}^{11-7}$ of the 62 patients with tuberculous pleural effusion showed sputum positivity for AFB (i.e. $11 \%$ ).

\section{Pleural Fluid Cytology}

Follador E.C. ${ }^{10}$-demonstrated predominance of lymphocytes and scarcity of mesothelial cells in tubercular effusion; Nance KV.12-cytology for malignancy was diagnostic in $71 \%$; Light RW.13-large number of neutrophils indicate the presence of bacterial pneumonia. Lymphocytes predominant in tubercular pleural effusion.

Cytology for malignant cells was positive in 33-87\%; Light ${ }^{14}$-demonstrated predominantly polymorphs in bacterial pneumonia.

All tubercular pleural effusion patients were put on treatment with antitubercular drugs along with steroids for rapid absorption of fluid and prevent fibrosis. Malignant pleural cases had pleurodesis and synpneumonic effusion responded to appropriate antibiotics given for 2 weeks. Empyema patients required intercostal tube drainage and antibiotics were given for 3 weeks. All patients received other supportive measures. Check $\mathrm{x}$-ray were done when and where necessary.

\section{REFERENCES}

1. Light RW. Anatomy of pleura pleural disease. Pleural diseases. $4^{\text {th }}$ ed. Philadelphia: Lippincott Williams and Wilkins 2001.

2. Richard W, Light. Pleural effusion. $N$ Engl J Med 2002;346:1971-7.

3. Maldhure BR, Bedarkar SP, Kulkarnl HR, et al. Pleural biopsy and adenosine deaminase in the pleural fluid in the diagnosis of tubercular pleural effusion. Ind J Tuberculosis 1994;41:161-4.

4. Park. Text book of preventive and social medicine. Epidemiology of tuberculosis. $18^{\text {th }}$ ed. Bansarilal publications park 2005.

5. Light RW, Establishing the diagnosis of tuberculous pleuritis. Arch Intern Med 1998;158(18):1967-8.

6. Prabhudesai PP, Mahashur AA, Mehta N, et al. Exudative pleural effusions in patients over forty years of age-an analysis of seventy six patients. Journal of post graduate medicine 1993;39(4):190-3.

7. Al-Quarain A, Al-Muhanna F, Larbi EB, et al. Pattern of pleural effusion in eastern province of Saudi Arabia a prospective study. East African Medical Journal 1994;71(4):246-9.

8. Cheng DS, Rodriguez RM, Rogers J, et al. Comparison of pleural fluid $\mathrm{pH}$ values obtained using blood gas machine, $\mathrm{pH}$ meter, and $\mathrm{pH}$ indicator strip. Chest 1998;114(5):1368-72.

9. Valdes L, Alvarez D, Jose SE, et al. Tuberculous pleurisy: a study of 254 patients. Arch Intern Med 1998;158(18):2017-21.

10. Follador EC, Pimentel M, Barbas CS, et al. Tuberculous pleural effusion: clinical and laboratory evaluation. Rev Hosp Clin Fac Med Sao Paulo 1991;46(4):176-9.

11. Subhakar K, Kotilengani K, Satyasri S. ADA activity in pleural effusion. Lung India 1991;9(2):57-60.

12. Nance KV, Shermer RW, Askin FB. Diagnostic efficacy of pleural biopsy as compared with that of pleural fluid examination. Mod Pathol 1991;4(3):320-4.

13. Light RW. Management of parapneumonic effusions. Arch Intern Med 1981;141(10):1339-41. 